\section{BOOK REVIEWS}

Women's Sexual Health (2nd edn). G Andrews (ed.). London, UK: Balliere Tindall, 2001. ISBN: 0-7020-2598-4. Cost: £35.95. Pages: 549 (hardback)

Nationally and internationally women's sexual health has achieved high priority in recent years. In the UK, successive political and National Health Service initiatives have promoted the role of nurses in delivering sexual health care, particularly in the community. This second edition of a well-established textbook for nurses is a comprehensive text on women's sexual health.

All chapters of this readable, reliable textbook are written by specialist nurses with expertise in their fields. Throughout, chapters are well referenced and supported by good suggestions for further reading and sources of further information and support. In many chapters case scenarios are used to good effect.

The first section, 'Women Today', puts sexuality in social, psychological and social contexts. There is an excellent introduction to the scope of women's sexuality and a good new chapter on ethico-legal issues. Other chapters sensitively explore sexual health issues for women from different cultural and religious backgrounds and for women with special needs. Another new chapter for this edition covers complementary therapies with a useful introduction to their backgrounds, strengths and limitations, as well as a sensible approach to their relationship to mainstream medical care. A good chapter on psychosexual problems explores the issues in a useful framework for the primary care setting.
The second section, 'Fertility', looks at fertility regulation, subfertility and sexuality around pregnancy. Although these topics are more medical in nature, they are dealt with in a holistic way.

The third section, 'Women's Health Issues', is a more medical section addressing gynaecological problems, cervical and breast screening, as well as menopausal and premenstrual complaints.

All the chapters were updated for this second edition. Some areas are inevitably outpaced by recent developments, particularly in contraception and menopause care; however, the chapters retain an overall validity of approach

This is a well-established text and reference source for student nurses/midwives and for qualified nurses extending their roles or studying for higher degrees. It would also be a refreshing read for medical students and doctors wanting a more holistic perspective on women's sexual health problems and their management.

Reviewed by Kate Weaver, MB ChB, MFFP Staff Grade Doctor, Dean Terrace Family Planning and Well Woman Clinic, Edinburgh, UK

Textbook of Perimenopausal Gynecology N Santoro and S R Goldstein (eds). New York, NY: Parthenon Publishing (available from CRC Press), 2003. ISBN: 1-84214-170-8. Price: £59.99. Pages: 176 (hardback)

This concise book with well-written text is written entirely by North American clinicians and is aimed at doctors working in women's health in the USA. Whilst this is interesting to read, from anecdotal experience in gynaecology and menopause clinics in the UK, I would say that the symptoms, concerns and problems which British women present with form a different profile to those of American women.
There are several chapters that give insightful and different views. The review of the physiology of the changes in body composition in midlife gave a new slant to weight gain in the menopausal years. The suggestion was made that postmenopausal women on hormone replacement therapy (HRT) actually gained less than those who were not on HRT. The chapter on sexuality also made interesting reading. It summarised the best predictor of midlife sexual function was the state of the individual's earlier experience. The other important message given throughout this book - was that clinicians dealing with women in midlife should avoid the 'quick-fix pill' trap. Rather than immediately prescribing HRT or testosterone for sexual problems in particular, doctors should look at the whole woman, her life, experiences, how she has dealt with them and her supporting relationships. There were some creative uses of oral contraception in the perimenopause and suggestions that reducing the pill-free interval from 7 to 5 days stops rises in folliclestimulating hormone and ovarian hormone production. More contentious issues such as that of the age at which the oral contraceptive should be discontinued, differed significantly from UK recommendations and might cause confusion to the reader who is not working regularly in this field.

Overall this is an excellent textbook for North American doctors but not appropriate for those on this side of the 'pond'. Whilst the overall ethos of viewing the midlife as a change rather than a disease is admirable, many women who attend menopause clinics might take issue with this point of view.

Reviewed by Alison Scott, MRCOG, DFFP Locum Consultant Gynaecologist, Dean Terrace Family Planning and Well Woman Clinic, Edinburgh, UK

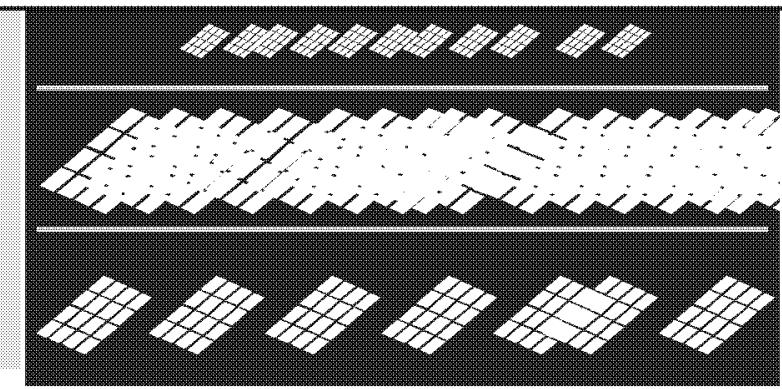

\title{
AVAILABLE NOW
}

Completely updated and revised, this unique reference book gives the names, addresses and telephone numbers (including out-of-hours contacts) for key community services throughout the UK including Family Planning.

- Details of the new NIIS National and Regional Structure

- Regional maps showing Strategic Health Authority areas

- Changes to PCTs and Social Care Trusts

ONI.Y $£ 21.95$

\section{Generous discounts for bulk orders}

\section{Telephone 01243576444}

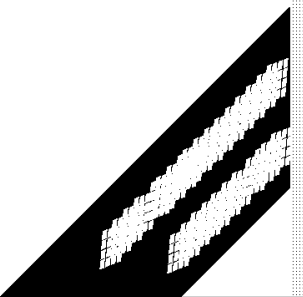

PMH Publications, PO Box 100, Chichester, PO18 8HD www. pmh.uk.con 